\title{
INFLUENCE OF DIFFERENT MATERIALS AND PREPARATION DESIGNS ON MARGINAL ADAPTATION AND FRACTURE RESISTANCE OF CAD/CAM FABRICATED OCCLUSAL VENEERS
}

\author{
Zeinab N. Emam * and Nada Ali A. Aleem**
}

\begin{abstract}
Statement of the problem: Thin, posterior occlusal veneers establish a conservative approach to conventional complete coverage restorations. Information about the proper material and its effect upon fracture resistance, which may affect the durability of the restoration, is still unknown.

Objective: This in-vitro study was carried out to assess the effect of variable materials and preparation designs on marginal fit and fracture resistance of CAD/CAM fabricated occlusal veneers.

Materials and Methods: A total number of sixty freshly extracted maxillary first premolars were collected. The selected teeth were inspected for being intact, non-restored and free from caries, cracks and severe occlusal erosive lesions. The teeth were chosen to be of comparable bucco-lingual and mesio-distal dimensions. All teeth were mounted along their long axis in epoxy resin templates. A standardized occlusal preparation (simulating advanced occlusal erosion) including enamel removal, dentin exposure and immediate dentin sealing were made. Teeth were randomly assigned equally to three test groups $(n=20)$ according to the material of the CAD/CAM blocks used for fabrication of the occlusal veneers, group (I): Lithium di-silicate glass ceramics (IPS e.max CAD, Ivoclar Vivadent, Schaan, Liechtenstein), group (II): Hybrid all-ceramic material (VITA ENAMIC, VITAZahnfabrik, Germany) and group (III): Nano ceramic reinforced resin composite (BRILLIANT Crios, Coltène/Whaledent AG, Switzerland). Each group was then sub-divided into two equal sub groups $(n=10)$ according the preparation design used for occlusal veneer, where subgroup (1): represented the minimally invasive occlusal veneer preparation resembling occlusal erosion. Subgroup (2): represented occlusal veneer preparation with marginal chamfer. Teeth were restored with $1.0 \mathrm{~mm}$ thickness occlusal veneers. Vertical marginal gap distance for all occlusal veneers was measured using stereomicroscope. Following Vertical marginal gap distance measurements, the samples were subjected to cyclic fatigue loading for 60000 cycles which is equivalent to six months clinical service. Then vertical marginal gap distance for all samples was recalculated after fatigue loading testing. Fracture resistance test was done using universal testing machine. The load to fracture for all samples was recorded in Newton. Data were collected, tabulated and statistically analyzed.
\end{abstract}

* Associate professor, Fixed Prosthodontics Department, Faculty of Dentistry, Cairo University, Egypt, Associate professor, Fixed prosthodontics Division, Oral and maxillofacial Department, Faculty of Dentistry, Umm Al Qura University, KSA.

** Assistant Professor, Conservative and Restorative Dentistry Department, Faculty of Dentistry, Umm Al Qura University, KSA. 
Results: Two ways ANOVA test results showed that CAD/CAM restorative materials used in this study, regardless of preparation design had a statistically significant effect on mean fracture resistance, whereas, preparation design regardless of type of material used had no statistically significant effect on mean fracture resistance. With Nano ceramic reinforced resin composite, hybrid ceramic and Lithium Di-silicate glass ceramics before or after cyclic fatigue loading; there was no statistically significant difference between marginal gap distances for the two preparation designs.

Conclusions: All the tested CAD/CAM materials showed fracture loads above the recommended minimum fracture strength for posterior restorations. CAD/CAM composite resin posterior occlusal veneers were superior to ceramic ones in terms of fracture resistance. All tested materials in both preparation designs whether before or after fatigue loading, exhibited marginal gap distance not exceeding that described in the literature as acceptable range.

KEY WORDS: All Ceramic, Occlusal veneer, Indirect composite, Hybrid ceramic, Vita Enamic, IPS e.max CAD, Minimally invasive, Different preparation designs, CAD/CAM, Marginal gap distance, Fracture resistance, Fatigue cyclic loading.

\section{INTRODUCTION}

Many factors may result in loss of tooth structure from occlusal surface, like para functional habits, bruxism, caries, erosion by gastric acids, diet and traumatic injuries. Minimally invasive approaches are highly recommended to preserve such dental tissues ${ }^{(1,2)}$. Erosive tooth wear has been of slight importance to restorative dentistry for several years. With increasing the importance of tooth existence, tooth wear continues to increase its importance in $21^{\text {st }}$ period ${ }^{(3)}$. Khan et al found a linear relationship between the number and size of erosive lesions and the age of the patients and explained this relation owing to changed life styles, amount and rate of consumption of acidic foods and drinks ${ }^{(4)}$. Management of sever erosive lesions might be affected by the size and extension of the defect ${ }^{(5)}$, which may reach dentin resulting in loss of vertical bite, enamel chipping of the incisal edges and cervical defects ${ }^{(6,7)}$.

Dental specialists are now available to produce high strength restorations that intermingle seamlessly with natural dentition while enduring posterior occlusal forces. This has led to innovative approaches for providing minimally invasive biomimetic dentistry, rebuilding of this erosive defects with indirect composite restoration, Occlusal veneers or partial crowns. With the availability of newer high strength all ceramic materials such as lithium di-silicate glass ceramics and hybrid all ceramic restorations encouraged in their choice as an enamel replacement ${ }^{(8)}$. This relies primarily on the strength and thickness of the material as well as on effective bonding to underlying dental tissues ${ }^{(9)}$ . In recent years; CAD/CAM technology has been progressively used to construct dental prosthesis ${ }^{(10)}$ .In attempts to enhance the mechanical properties of restoration, industrially made $\mathrm{CAD} / \mathrm{CAM}$ ceramic blocks have been introduced to dentistry (11). Manufacturing ceramics under industrial conditions resulted in remarkable reduction in voids, flaws and cracks in comparison with conventional laboratory techniques ${ }^{(12)}$. Furthermore, the innovative adhesive technology might lead to superior preservation of residual tooth structure which is a major concern in restorative dentistry ${ }^{(13,14)}$. 
The performance of CAD/CAM nano hybrid composite resin restorations have also increased in last years ${ }^{(15)}$, through a superior bond to underlying structure resulting in appropriate stress transfer, low abrasiveness of opposing teeth lead to enamel preservation as well as low elastic modulus allowing absorption of functional stresses ${ }^{(16)}$.

The development of the Nano-scaled fillers offers the advantage of great esthetics, exceptional polishability and high strength ${ }^{(17,18)}$.

Lately, an innovative hybrid ceramic material has been presented to the market. This hybrid material combines the characteristics of a ceramic and a composite. It is composed of a porous ceramic matrix with the pores filled with a polymeric material. Moreover to the high degree of elasticity, hybrid ceramics confirms high strength after adhesive bonding, therefore allowing the decrease of the restoration thickness ${ }^{(19)}$.

Lithium disilicate glass ceramics could be typically fabricated through heat pressed techniques or milled with CAD/CAM systems. The IPS e.max CAD block is a partially crystallized block, allowing the material to be easily milled. After milling the block into the desired restoration, a recrystallization process takes place at $850^{\circ} \mathrm{C}$ for 10 minutes, through which the lithium meta-silicate is transformed into lithium disilicate crystals. This transformation provides the restoration with its final mechanical and aesthetic properties. The flexural strength of IPS e.max CAD after crystallizing is about $360 \mathrm{MPa}{ }^{(20)}$.

Marginal fit is also one of the important criteria for long term success of dental restoration ${ }^{(21)}$. The presence of marginal discrepancies in the dental restoration exposes the luting cement to oral environment. The larger the discrepancy, the more rapid the rate of cement dissolution, periodontal diseases, esthetic problems which might result in failure of dental restoration ${ }^{(22)}$.
Fractures of all ceramic restorations were mentioned in various literatures as the most common cause for the failure of these restorations ${ }^{(23-25)}$. Moreover, the fracture resistance of occlusal veneers might be influenced by the properties of the underlying supporting structures such as its elastic modulus, the bond strength, thickness of all ceramic restorations, or the preparation design ${ }^{(26,27)}$.

Sasse et al, (26) evaluated the fracture resistance of occlusal veneers made of lithium disilicate produced in different thicknesses and bonded to different substrates. They stated that the thickness of the occlusal veneers should not fall below 0.7-1.0 mm regardless the type of substrate. Therefore, the objective of our study was to evaluate the influence of different materials IPS e.max CAD, hybrid ceramic (Vita Enamic) and nano ceramic reinforced resin composite (BRILLIANT Crios) and two preparation designs (the minimally invasive occlusal veneer preparation which resembling occlusal erosion and occlusal veneer preparation with chamfer finish line.) on vertical marginal gap distance and fracture resistance of CAD/CAM fabricated occlusal veneers. The following null hypotheses were tested (1) the materials and preparation designs have no influence on load to fracture and marginal quality and (2) the cyclic fatigue loading has no effect on vertical marginal gap distance.

\section{MATERIAL AND METHODS}

\section{Teeth selection and Sample grouping}

A total of sixty freshly extracted maxillary first premolars were collected. The selected teeth were inspected for being intact, non-restored and free from caries, cracks and severe occlusal erosive lesions. The selected teeth were chosen to be of comparable bucco-lingual and mesio-distal dimensions and morphology. The teeth were cleaned and disinfected by immersion in $0.5 \%$ sodium hypochlorite solution for 15 minutes and stored in distilled water till use. Storage period did not exceed two weeks. 
Then the roots of all teeth were mounted along their long axis into epoxy resin mounting templates (Polypoxy 700, polymer, chemical industries for construction Co., CIC, Egypt) using a cylindrical Teflon mold at a level of $3 \mathrm{~mm}$ apical to their cemento -enamel junctions. Teeth were randomly and equally assigned to three test groups $(n=20)$ according to the material of the CAD/CAM blocks for fabrication of the occlusal veneers, group (I): Lithium di-silicate glass ceramics (IPS e.max CAD, Ivoclar Vivadent, Schaan, Liechtenstein), group
(II): Hybrid all-ceramic material (VITA ENAMIC, VITA Zahnfabrik, Germany) and group (III): Nano ceramic reinforced resin composite (BRILLIANT Crios, Coltène, Whaledent AG, Switzerland). Each group was then sub-divided into two equal sub groups ( $\mathrm{n}=10)$ according the preparation design used for occlusal veneer preparation, where subgroup (1), represented the minimally invasive occlusal veneer preparation which resembling occlusal erosion. Subgroup (2) represented occlusal veneer preparation with chamfer finish line. Table (1)

TABLE (1) The chemical composition and Manufacturers of the materials used in this study.

\begin{tabular}{|c|c|c|}
\hline Material & Composition & Manufacturer \\
\hline $\begin{array}{l}\text { Lithium di-silicate glass } \\
\text { ceramics (IPS e.max CAD) }\end{array}$ & $\mathrm{SiO}_{2}, \mathrm{Li}_{2} \mathrm{O}, \mathrm{K}_{2} \mathrm{O}, \mathrm{P}_{2} \mathrm{O}_{5}, \mathrm{ZrO}_{2}, \mathrm{ZnO}, \mathrm{Al}_{2} \mathrm{O}_{3}, \mathrm{MgO}$,Pigments & $\begin{array}{l}\text { Ivoclar Vivadent, } \\
\text { Schaan, Liechtenstein }\end{array}$ \\
\hline $\begin{array}{l}\text { Dental hybrid ceramics } \\
\text { (VITA ENAMIC) }\end{array}$ & $\begin{array}{l}\text { Ceramic part: } 86 \% \text { wt. } \\
\mathrm{SiO}_{2}(58-63 \%), \mathrm{Al}_{2} \mathrm{O}_{3}(20-23 \%), \mathrm{Na}_{2} \mathrm{O}(9-11 \%), \mathrm{K}_{2} \mathrm{O}(4- \\
6 \%), \mathrm{B}_{2} \mathrm{O}(0.5-2 \%), \mathrm{ZrO}_{2}(<1 \%), \mathrm{KaO}(<1 \%) \\
\text { Polymer part: } 14 \% \text { wt (UDMA,TEGDMA) }\end{array}$ & $\begin{array}{l}\text { VITA Zahnfabrik, } \\
\text { Germany }\end{array}$ \\
\hline $\begin{array}{l}\text { Nano ceramic reinforced resin } \\
\text { composite } \\
\text { (BRILLIANT Crios) }\end{array}$ & $\begin{array}{l}\text { Barium glass }<1.0 \mu \mathrm{m} \text {, Amorphous silica } \mathrm{SiO}<20 \mathrm{~nm} \text {. } \\
\text { Resin matrix: Cross-linked methacrylates } \\
\text { Pigments: ferrous oxide \& titanium dioxide. }\end{array}$ & $\begin{array}{l}\text { Coltène/Whaledent AG, } \\
\text { Switzerland }\end{array}$ \\
\hline $\begin{array}{l}\text { RelyX Unicem } \\
\text { Self-adhesive, dual-cure resin } \\
\text { cement }\end{array}$ & $\begin{array}{l}\text { Powder: } \\
\text {-Alkaline (basic)fillers } \\
\text {-Silanted fillers } \\
\text {-Initiator components } \\
\text {-Pigments } \\
\text { Liquid: } \\
\text { - Methacylate monomers containing phosphoric acid groups. } \\
\text { - Methacylate monomers } \\
\text { - Initiator components } \\
\text {-stabilizers }\end{array}$ & $\begin{array}{l}\text { 3M ESPE, St. Paul, } \\
\text { Germany }\end{array}$ \\
\hline $\begin{array}{l}\text { Adper Easy Bond } \\
\text { Self-etch adhesive system }\end{array}$ & $\begin{array}{l}\text {-BisGMA; HEMA; water (10-15 Wt\%) } \\
\text { - Ethanol (10-15Wt\%) } \\
\text {-phosphoric acid-6-methacryloxy hexylesters; } \\
\text {-silane-treated silica } \\
\text {-1,6-hehadeniol dimethacrylate } \\
\text {-copolymer of acrylic and itaconic acid(dimethylamino) ethyl } \\
\text { methacrylate } \\
\text { - camphorquinone } \\
\text { - 2,4,6trimethylbenzoyldiphenylphosphine oxide }\end{array}$ & $\begin{array}{l}\text { 3M ESPE, St. Paul, } \\
\text { Germany }\end{array}$ \\
\hline $\begin{array}{l}\text { Scotchbond } \\
\text { Universal Etchant }\end{array}$ & $37.5 \%$ phosphoric acid & $\begin{array}{l}\text { 3M ESPE, St. Paul, } \\
\text { Germany }\end{array}$ \\
\hline
\end{tabular}




\section{Tooth preparation:}

An effort to standardize tooth preparation, all teeth used in this study was prepared by a single experienced prosthodontist for sample preparation. For Subgroup (1): The minimally invasive occlusal veneer preparation, standardized tooth preparation with the purpose of simulating advanced occlusal erosion was applied. The occlusal reduction was set as $1 \mathrm{~mm}^{(8,28)}$. Four depth grooves were made in the occlusal surface following tooth anatomy with a cylindrical coarse diamond bur with a $0.8 \mathrm{~mm}$ diameter (835 KRM 314008, Komet, Lemgo, Germany). Then these depth grooves were connected by removing enamel portions in between them with a round-ended cylindrical diamond bur (836 KR 314 018, Komet).The buccal and palatal margins were maintained at approximately 5.0 $\mathrm{mm}$ from the CEJ .The occlusal preparation was finished with a fine-grit diamond bur (8846 KR 314 016, Komet). For subgroup (2) preparation was made following exactly the steps done as subgroup (1), then chamfer finish line was prepared on the top of the axial wall by using tapered bur with a noncutting guide pin at its tip (6856P 314 018, Komet) and finished with a fine-grit bur (8856 $\mathrm{P}$ 314 018, Komet). The prepared surfaces were then polished with abrasive rubber points (9608 314 030, Komet) ${ }^{(28)}$.In order to ensure a uniform and equal amount of occlusal reduction for each tooth, two indexes were made by addition silicon impression material (3M ESPE, Imprint II, Germany) using custom-made impression trays .Indexes were taken in mesio-distal and bucco-lingual directions. In both groups, cuspal inclination was kept as constant as possible $^{(8)}$.Figure 1, 2

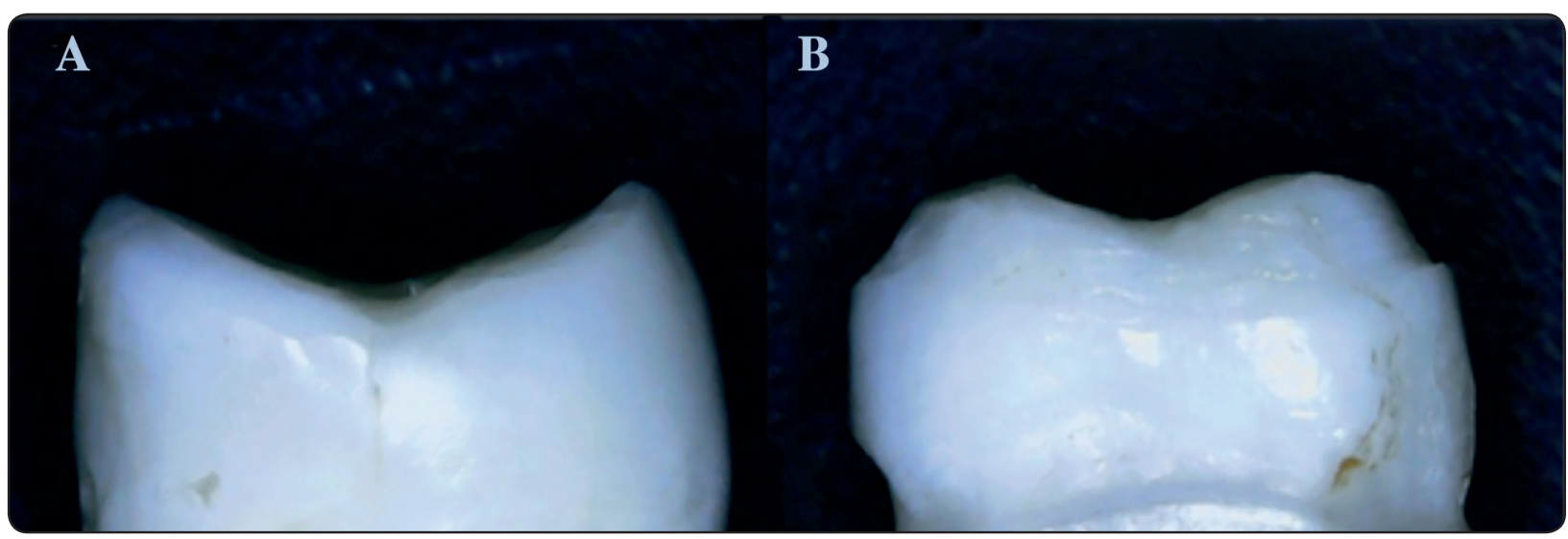

Fig. (1) The preparation designs used for occlusal veneer preparation, (A).represents subgroup (1) the minimally invasive occlusal preparation resembling occlusal erosion. (B). represents subgroup (2) occlusal preparation with chamfer finish line.

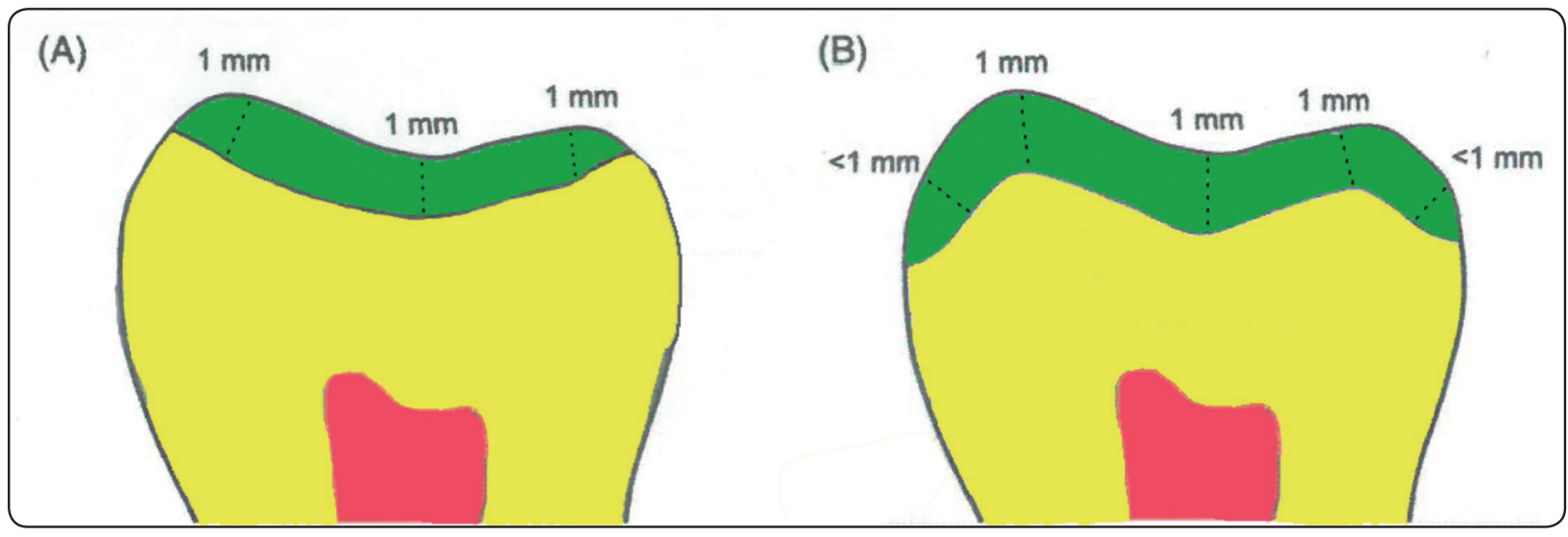

Fig. (2) Occlusal veneer preparation design where (A) represents subgroup (1) the minimally invasive occlusal preparation, and (B) represents subgroup (2) occlusal preparation with chamfer finish line. (Bucco-Lingual Section) 


\section{Immediate dentin sealing}

Dentin surfaces exposed after the tooth preparation process were immediately sealed with a self-etch adhesive system (Adper Easy Bond SelfEtch Adhesive, 3M ESPE, St. Paul, Minnesota) following the manufacturer instructions. The adhesive was applied on the exposed dentine with a light brushing motion for 20 seconds and gently airdried for 5 seconds, then light-cured for 10 seconds with a LED lamp at $1200 \mathrm{~mW} / \mathrm{cm} 2$ (Bluephase, Ivoclar Vivadent, USA). All specimens were stored in normal saline solution for 24 hours at $37^{\circ} \mathrm{C}$ before the restorative procedures.

\section{Occlusal veneers fabrication}

All prepared teeth were scanned using CEREC InLab scanner (InEos Sirona, Germany).

The image of the scanned prepared tooth appeared on the screen. The acquired image was transferred to the CAD software for designing. CAD/CAM blocks of IPS E.max, Vita Enamic and Brilliant, Crios were used to construct occlusal veneers using $\mathrm{CAD} / \mathrm{CAM}$ system software (InLab Sw4.0, Sirona)for designing the restoration .The parameters for occlusal veneers were adjusted to be as follows: Each occlusal veneer was set to be 1 $\mathrm{mm}$ uniform thickness all over the occlusal surface and $40 \mu \mathrm{m}$ cement thickness. After selection of the required anatomy and extension of the occlusal veneer, the design was saved to be ready for milling steps. CAD/CAM system software ( Cerec -InLab MC XL ,Sirona, Germany) was used for milling after choosing the type of the block. Following the milling procedures, the IPS e.max CAD oclusal veneers [group (I)] was crystallized in programmat furnace (Programmat P500, Ivoclar, Vivadent, Schann, Lieichtein) at $850^{\circ}$ for thirty minutes. For Vita enamic occlusal veneers and Brilliant,Crios [group (II) and group (III)], the veneers were finished and smoothed according to manufacturer instructions without any sintering or crystallization process using the manufacturer recommended polishing set.

\section{Restoration bonding procedures}

After the milling procedure, all veneers were thoroughly inspected for any defects or cracks and evaluated for proper fit. The fitting surfaces for group (I) and (II) occlusal veneers were etched with 5\% hydrofluoric acid (IPs Ceramic etchant gel ivoclar, Vivadent) for twenty seconds, rinsed off and cleansed in ultrasonic cleaner for three minutes, then,silane coupling agent (Variolink S bond, Ivoclar, Vivadent) was applied to the fitting surfaces of the occlusal veneers and allowed to dry for one minute then air dispersed to obtain a thin coat. For Group III, the fitting surfaces were sandblasted with $40 \mu \mathrm{m}$ aluminum oxide particles at 1.5 bar as recommended by the manufacturer.

Prior to cementation procedures, sealed dentin surfaces were air abraded with an intra-oral air abrasion device with $40 \mu \mathrm{m}$ aluminum oxide particles at 30 psi (Cojet System, 3M, St. Paul, Minnesota) until the surfaces became dull. Prepared surfaces were then cleaned with alcohol and dried with oil-free pressurized air, as recommended by the manufacturer.

After cleaning procedures, prepared tooth surfaces were etched with $37.5 \%$ phosphoric acid (Scotchbond $^{\mathrm{TM}}$ Universal Etchant, 3M ESPE, St. Paul, Minnesota) for $15 \mathrm{~s}$, thoroughly rinsed and dried without desiccating dentin. Veneers were bonded using freshly mixed self-adhesive, dualcure resin cement (RelyX Unicem, 3M ESPE, St. Paul, Minnesota). According to the manufacturer's recommendation, where the auto mixed cement was dispensed directly onto the bonding surface of the fabricated veneers. A static load of $3 \mathrm{Kg}$ was applied on the occlusal surface of the cemented veneers using a specially designed cementing device. Excess cement was light cured for 2 seconds and then removed in the cement's gel state with an 
explorer, and then final light curing was completed for $15 \mathrm{~s}$ per restoration surface at $1400 \mathrm{~mW} / \mathrm{cm} 2$. After restoration bonding, all teeth were returned to $37^{\circ} \mathrm{C}$ distilled water storage until testing.

\section{Vertical marginal gap distance measurements}

Restored teeth were taken two times for analysis of marginal quality, Within 48 hours after occlusal veneers cementation, and at the end of fatigue loading test.

Vertical margin gap distance of all veneers was measured using an image analysis system. This method uses image analysis software (Image J-1b, USA) in combination with a stereomicroscope (Olympus, SZ-PT: Japan) ${ }^{(29) .}$

For all samples, measurements were taken for each tooth along the circumference of tooth/ restoration margin at equally spaced points on each of the buccal, mesial, lingual and distal surfaces. Two added marks for each surface were marked 2 $\mathrm{mm}$ mesial and distal to the middle points to obtain a total of twelve measuring points for each tooth/ restoration margin.

For each occlusal veneer, the area of interest was captured by CCD digital camera (DP-10 Olympus, Japan) mounted on the stereomicroscope. The vertical margin gap distance between the cervical margin of the veneers and the tooth margin was assessed at the previously marked points. These readings were calculated using the image analysis software.

Following vertical marginal gap distance measurements, the samples were subjected to fatigue loading. Mechanical aging was performed using programmable equipment; ROBOTA chewing simulator integrated with thermo-cyclic protocol (Model Ach-09075, Germany).

The specimens were embedded in Teflon housing in the lower sample holder. A weight of $10 \mathrm{~kg}$, which is comparable to $100 \mathrm{~N}$ of chewing force, was exerted. The test was repeated 60000 times to clinically simulate 6 months chewing condition, according to previous study. ${ }^{(30)}$ Then vertical marginal gap distance for all samples were recalculated after the fatigue loading testing using the same method as mentioned before.

\section{Fracture resistance testing}

All samples were individually mounted on a computer-controlled material testing machine (Model 3345; Instron Industrial Products, Norwood, MA, USA) with a loadcell of $5000 \mathrm{~N}$ and data were recorded using computer software. Samples were secured to the lower fixed compartment of testing machine by tightening screws. Fracture test was done by compressive mode of load applied occlusally using a metallic rod with spherical tip (5.8 $\mathrm{mm}$ diameter for crown samples) attached to the upper movable compartment of testing machine traveling at cross-head speed of $1 \mathrm{~mm} / \mathrm{min}$ with tin foil sheet in-between to achieve homogenous stress distribution and minimization of the transmission of local force peaks. The load at failure manifested by an audible crack and confirmed by a sharp drop at load-deflection curve recorded using computer software (Bluehill Lite Software Instron ${ }^{\circledR}$ Instruments). The load required to fracture was recorded in Newton. Data were collected, organized in tables and statistically analyzed.

\section{Statistical Analysis}

Data were presented as mean, standard deviation (SD), median and range values. For parametric data; two-way Analysis of Variance (ANOVA) was used to study the effect of material type, preparation design and their interaction on mean fracture resistance. Bonferroni's post-hoc test was used for pair-wise comparisons when ANOVA test is significant. The significance level was adjusted at $\mathrm{P} \leq 0.05$. Statistical analysis was performed with IBM SPSS Statistics for Windows, Version 23.0. Armonk, NY: IBM Corp. 


\section{RESULTS:}

\section{Fracture resistance $(\mathbf{N})$}

Two-way ANOVA results showed that different materials used in this study had a statistically significant effect on mean fracture resistance while preparation design regardless of material type had no statistically significant effect on mean fracture resistance. The interaction between the two variables had no statistically significant effect on mean fracture resistance indicating that the variables are independent from each other. Table (2)

Regardless the preparation design used in this study; there was a statistically significant difference between mean fracture resistance of different materials $(P$-value $<0.001$, Effect size $=0.865)$. Pair-wise comparisons between materials revealed that composite showed the statistically significantly highest mean fracture resistance followed by hybrid ceramic, while lithium di-silicate showed the statistically significant lowest mean fracture resistance, Whereas there was no statistically significant difference between mean fracture resistance of the two preparation designs $(P$-value $=$ 0.916, Effect size $=0.001)$. Table 2, Figure 3.

\section{Marginal gap distance $(\mu \mathrm{m})$}

With minimally invasive occlusal veneer preparation design either before or after cyclic

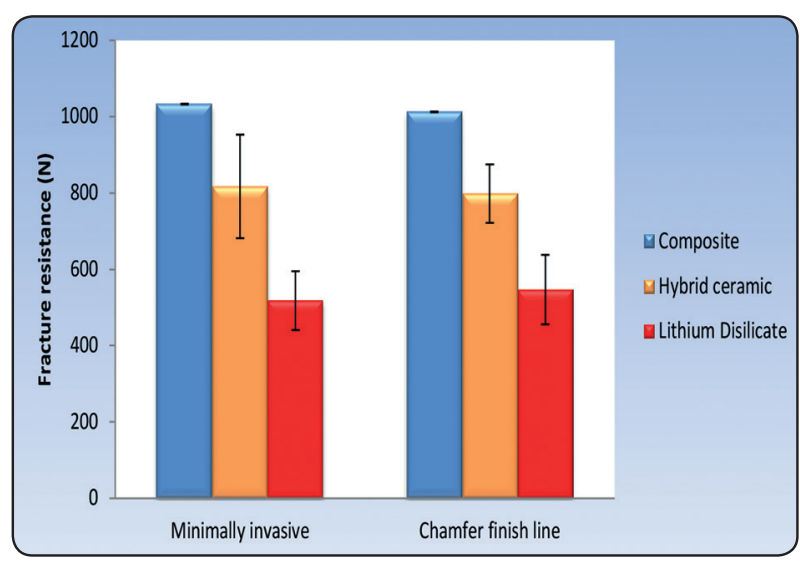

Fig. (3) Bar chart representing mean and standard deviation values for fracture resistances $(\mathrm{MPa})$ of different variables

fatigue; whether with composite, hybrid ceramic or Lithium di-silicate before cyclic fatigue; there was no statistically significant difference between marginal gap distances of the two preparation designs $(P$-value $=0.663$, Effect size $=0.177)$, $(P$-value $=0.930$, Effect size $=0.035)$ and $(P$-value $=0.337$, Effect size $=0.396$ ), respectively. Similarly with composite, hybrid ceramic or Lithium disilicate after cyclic fatigue; there was no statistically significant difference between marginal gap distances of the two preparation designs $(P$-value $=$ 0.111 , Effect size $=0.685),(P$-value $=0.435$, Effect size $=0.025)$ and $(P$-value $=0.326$, Effect size $=0.409)$, respectively. Table $(3)$

TABLE (2) The mean, standard deviation (SD) values and results of two-way ANOVA test for comparison between fracture resistances values $(\mathrm{MPa})$ with different interactions of variables.

\begin{tabular}{|c|c|c|c|c|c|c|c|c|}
\hline \multirow[t]{2}{*}{ Preparation technique } & \multicolumn{2}{|c|}{ Composite } & \multicolumn{2}{|c|}{ Hybrid ceramic } & \multicolumn{2}{|c|}{ Lithium Disilicate } & \multirow[t]{2}{*}{$P$-value } & \multirow{2}{*}{$\begin{array}{c}\text { Effect size (Partial } \\
\text { eta squared) }\end{array}$} \\
\hline & Mean & SD & Mean & SD & Mean & SD & & \\
\hline Minimally invasive & $1033^{\mathrm{A}}$ & 135.7 & $817.3^{\text {в }}$ & 77 & $518^{\mathrm{C}}$ & 74.1 & $<0.001^{*}$ & 0.780 \\
\hline Chamfer finish line & $1012.6^{\mathrm{A}}$ & 76.6 & $798.4^{\text {в }}$ & 91.1 & $546.9^{\mathrm{C}}$ & 57.1 & $<0.001 *$ & 0.742 \\
\hline$P$-value & \multicolumn{2}{|c|}{0.718} & \multicolumn{2}{|c|}{0.740} & \multicolumn{2}{|c|}{0.611} & & \\
\hline $\begin{array}{c}\text { Effect size (Partial eta } \\
\text { squared) }\end{array}$ & \multicolumn{2}{|c|}{0.006} & \multicolumn{2}{|c|}{0.005} & \multicolumn{2}{|c|}{0.011} & & \\
\hline
\end{tabular}

*: Significant at $P \leq 0.05$, Different superscripts in the same row are statistically significantly different 


\section{Effect of cyclic fatigue loading:}

Using minimally invasive design with composite, hybrid ceramic or Lithium di-silicate; there was a statistically significant increase in median marginal gap distances after cyclic fatigue $(P$-value $=0.002$, Effect size $=0.883),(P$-value $=0.002$, Effect size $=$ $0.883)$ and $(P$-value $=0.002$, Effect size $=0.833)$, respectively.
For chamfer finish line with composite, hybrid ceramic or Lithium Disilicate; there was a statistically significant increase in median marginal gap distances after cyclic fatigue $(P$-value $=0.003$, Effect size $=0.861),(P$-value $=0.002$, Effect size $=$ $0.883)$ and $(P$-value $=0.002$, Effect size $=0.833)$, respectively. Table (4), Figure $(4,5)$

TABLE (3) Descriptive statistics and results of Mann-Whitney U test for comparison between marginal gap distances $(\mu \mathrm{m})$ of the two preparation designs and different materials used.

\begin{tabular}{|c|c|c|c|c|c|c|c|}
\hline \multirow{2}{*}{$\begin{array}{l}\text { Cyclic } \\
\text { fatigue }\end{array}$} & \multirow[t]{2}{*}{ Material } & \multicolumn{2}{|c|}{ Minimally invasive } & \multicolumn{2}{|c|}{ Chamfer finish line } & \multirow{2}{*}{$P$-value } & \multirow{2}{*}{$\begin{array}{c}\text { Effect size } \\
\qquad(d)\end{array}$} \\
\hline & & Mean (SD) & Median (Range) & & & & \\
\hline \multirow[t]{3}{*}{ Before } & Composite & $16.5(4.2)$ & $16(8-24)$ & $17.7(7.4)$ & $18(8-30)$ & 0.663 & 0.177 \\
\hline & Hybrid ceramic & $14.7(5.7)$ & $14(8-26)$ & $14.2(5.1)$ & $12(8-24)$ & 0.930 & 0.035 \\
\hline & Lithium Disilicate & $13.2(4)$ & $12(8-21)$ & $12(3.9)$ & $10.5(8-20)$ & 0.337 & 0.396 \\
\hline \multirow[t]{3}{*}{ After } & Composite & $44.8(11.5)$ & $44.7(20-63.3)$ & $36(15.1)$ & $31.9(14.9-66.7)$ & 0.111 & 0.685 \\
\hline & Hybrid ceramic & $48.4(17.8)$ & $45.1(27.5-90.7)$ & $52.8(17.8)$ & $50.9(27.5-87.7)$ & 0.435 & 0.025 \\
\hline & Lithium Disilicate & $46.7(17.1)$ & $44.5(27.4-88.2)$ & $49.7(16)$ & $52.9(27.5-82.6)$ & 0.326 & 0.409 \\
\hline
\end{tabular}

\section{*: Significant at $P \leq 0.05$}

TABLE (4) Descriptive statistics and results of Wilcoxon signed-rank test for comparison between marginal gap distances $(\mu \mathrm{m})$ before and after cyclic fatigue.

\begin{tabular}{|c|c|c|c|c|c|c|c|}
\hline \multirow{2}{*}{$\begin{array}{l}\text { Preparation } \\
\text { design }\end{array}$} & \multirow{2}{*}{ Material } & \multicolumn{2}{|c|}{ Before cyclic fatigue } & \multicolumn{2}{|c|}{ After cyclic fatigue } & \multirow{2}{*}{$P$-value } & \multirow{2}{*}{$\begin{array}{l}\text { Effect } \\
\text { size }(r)\end{array}$} \\
\hline & & Mean (SD) & Median (Range) & Mean (SD) & Median (Range) & & \\
\hline \multirow{3}{*}{$\begin{array}{l}\text { Minimally } \\
\text { invasive }\end{array}$} & Composite & $16.5(4.2)$ & $16(8-24)$ & $44.8(11.5)$ & $44.7(20-63.3)$ & $0.002 *$ & 0.883 \\
\hline & Hybrid ceramic & $14.7(5.7)$ & $14(8-26)$ & $48.4(17.8)$ & $45.1(27.5-90.7)$ & $0.002 *$ & 0.883 \\
\hline & Lithium Disilicate & $13.2(4)$ & $12(8-21)$ & $46.7(17.1)$ & $44.5(27.4-88.2)$ & $0.002 *$ & 0.883 \\
\hline \multirow{3}{*}{$\begin{array}{l}\text { Chamfer } \\
\text { finish line }\end{array}$} & Composite & $17.7(7.4)$ & $18(8-30)$ & $36(15.1)$ & $31.9(14.9-66.7)$ & $0.003 *$ & 0.861 \\
\hline & Hybrid ceramic & $14.2(5.1)$ & $12(8-24)$ & $52.8(17.8)$ & $50.9(27.5-87.7)$ & $0.002 *$ & 0.883 \\
\hline & Lithium Disilicate & $12(3.9)$ & $10.5(8-20)$ & $49.7(16)$ & $52.9(27.5-82.6)$ & $0.002 *$ & 0.883 \\
\hline
\end{tabular}




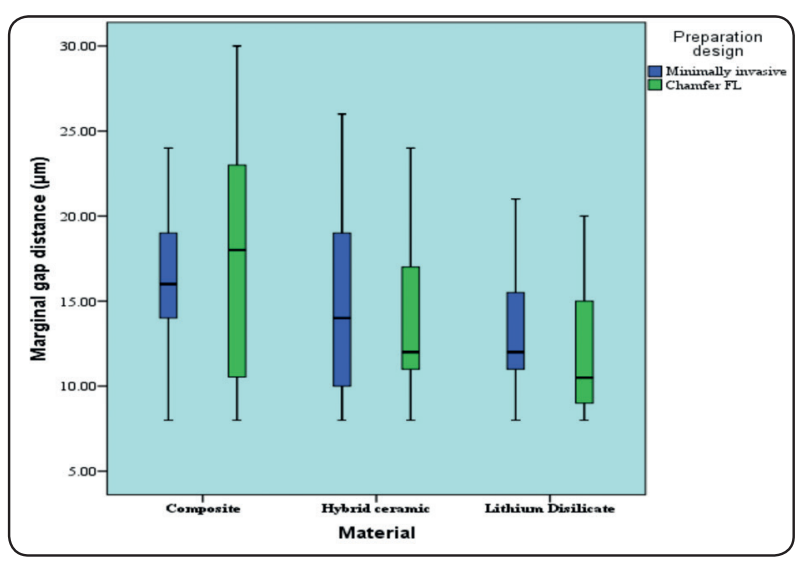

Fig. (4) Box plot representing median and range values for marginal gap distance of different materials and preparation designs before cyclic fatigue

\section{DISCUSSION}

This investigation was carried on to evaluate the fracture resistance and marginal gap distance of occlusal veneer restorations with two preparation designs that were fabricated from lithium di-silicate glass ceramics, hybrid all-ceramic material and nanoceramic reinforced resin composite using $\mathrm{CAD} /$ CAM technology. According to the results of the study: the type of the material significantly affected values of fracture strength and mean marginal gap distance but not the preparation design, so the null hypothesis would be partially rejected.

In the present study, human natural teeth were chosen due to their elastic characteristics, their bonding ability, and strength that better match the situation in the clinic ${ }^{(31)}$. All teeth were stored in saline till use to prevent them from drying out and becoming brittle ${ }^{(28)}$. The irregular occlusal anatomy of human natural teeth crowns make it difficult to be restored with occlusal veneers having a homogenous uniform thickness, so CAD/CAM technology was chosen in this study because of its ability to control thickness and geometry of the restorations during fabrication process, it also provides standardized fabrication technique avoiding laboratory variations due to trails involved in the fabrication technique ${ }^{(8)}$.

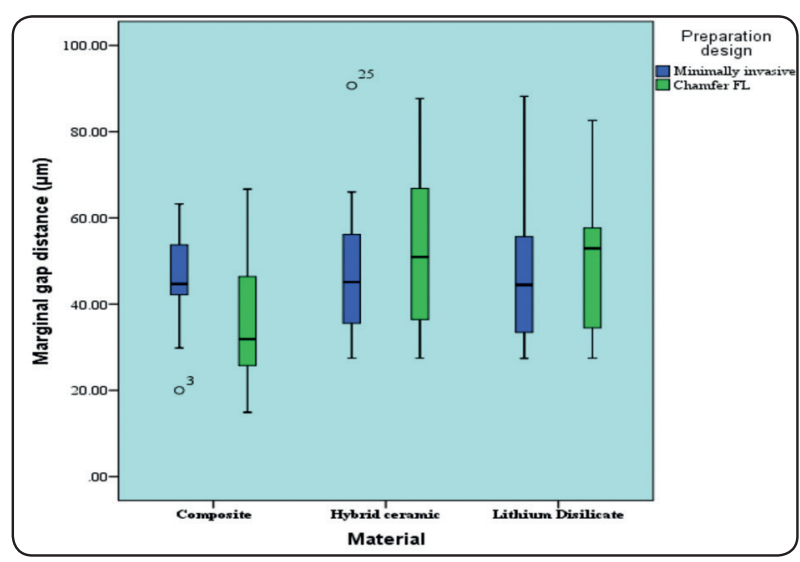

Fig. (5) Box plot representing median and range values for marginal gap distance of different materials and preparation designs after cyclic fatigue (Circles represent outliers)

Occlusal veneers are thin overlay restorations with a non-retentive design. Currently, they have become more and more popular as a conservative treatment for occlusal abrasion or erosion. Occlusal veneers have been introduced as an alternative to replace onlays and traditional full coverage crowns. Two preparation designs were selected in the present investigation namely; a minimally invasive design where only the occlusal surface was included in the preparation and chamfer finish line preparation where an occlusal preparation of one $\mathrm{mm}$ depth was carried on together with a marginal chamfer finish line and The designs of the preparations were selected according to the general endorsements and preparation guidance for minimally invasive partial coverage restorations ${ }^{(32,33)}$.

Recently, computer milled ceramic and nonceramic materials have become prevalent because of their high esthetic qualities. Three materials were chosen to conduct this study including, lithium disilicate glass ceramics, hybrid all-ceramic material and nano-ceramic reinforced resin composite using CAD/CAM technology. Most mechanical failure of dental restorations occurs due to fatigue fracture as a result of repeated occlusal loading during function ${ }^{(34)}$ moreover, the durability of dental restorations under cyclic loading is more clinically pertinent, as failure 
due to fatigue happens in subcritical loads. In the present protocol a load of $100 \mathrm{~N}$ was used which was selected to resemble average of normal occlusal load among individuals that ranges between 10 to $120 \mathrm{~N}$ during mastication ${ }^{(3)}$.

In the current study, there was a statistically significant difference between mean fracture resistances of different materials (P-value $<0.001$ ). Pair-wise comparisons between materials revealed that composite showed the statistically significantly highest mean fracture resistance, Hybrid ceramic showed statistically significantly lower mean value, and Lithium Di-silicate showed the statistically significantly lowest mean fracture resistance. These findings could be because of the fact that fatigue failure occurs in three stages including; crack nucleation then propagation and finally fracture occurs ${ }^{(35,36)}$ this kind of failure typically occurs in stiff ceramics while composite materials demonstrate more favorable resistance to such fatigue ${ }^{(37)}$. On the other hand, the presence of polymers in the microstructure of hybrid ceramics has made them more resistance to crack propagation than their conventional ceramic counterparts ${ }^{(38)}$.

These findings were in agreement with a study compared the fatigue resistance of all-ceramic fullcoverage restorations with resin composite, and their results were as follows, restorations made of resin composite showed significantly better survival when subjected to cyclic loading ${ }^{(39)}$.

Another study carried out by Magne et al., $2010^{(40)}$ where they used cyclic loading on occlusal veneers which were CAD/CAM-fabricated from two ceramic materials including lithium disilicate and one composite material, the resin composite occlusal veneers had significantly increased fatigue resistance in such conservative applications with $100 \%$ survival after all loading cycles (up to $1400 \mathrm{~N}$ ) compared to the $30 \%$ and $0 \%$ survival rates represented by the ceramic groups. These results could be contributed to the fact that structural integrity of multilayered structure such as teeth with bonded restorations is related to the differences in elastic moduli between tooth tissues, the luting material and the restoration and not by the flexural strengths of the restorative materials (40). So the significantly higher fracture resistance of the composite group could be a result of the relative similarity of elasticity moduli between resin composite and dentin ${ }^{(40)}$.

Schlichting et al., 2011 ${ }^{(8)}$ investigated the fatigue resistance of thinner $(0.6 \mathrm{~mm})$ occlusal veneer restorations milled from the blocks of the same materials and concluded that, composite veneers had significantly higher fatigue resistance compared to lithium di- silicate, they explained these results by the close similarity between dentin and composite moduli of elasticity and they stated that, strength data alone cannot predict the failure behavior of such restorations.

On the other hand, the current results disagree with a study investigated mechanical properties and fatigue behavior of some contemporary used dental ceramics which found that the maximum load at fracture of hybrid ceramic material was significantly lower than that lithium di-silicate ${ }^{(34)}$ but, despite of this result, authors concluded that hybrid all ceramic material was the most reliable one. A related study aimed to compare the fracture resistance of adhesively bonded machined blocks of lithium disilicate and hybrid all ceramic restorations, they found that hybrid all ceramic specimens showed significantly lower fracture resistance than lithium di-silicate group ${ }^{(41)}$. An explanation for the diversity in results could be attributed to the different surface treatment methods together with different bonding protocols. In the present study, immediate dentin sealing protocol was employed which represents the gold standard in such cases as the freshly cut dentin provides the most favorable substrate for bonding ${ }^{(42,43)}$. 
In the present investigation there was no statistically significant difference between mean fracture resistances of the two preparation designs, which means that there was no effect of the preparation design on fracture resistance of the three used materials. These findings were in agreement with those of another study that employed two preparation designs and evaluated their effect on fatigue resistance of lithium di-silicate glass ceramic and found that preparation designs had no significant effect on the tested mechanical property ${ }^{(28)}$. Unfortunately information about thin and ultrathin CAD/CAM occlusal veneers and the influence of their design on the fracture resistance of such restoration are still limited ${ }^{(26,44,45)}$.

Marginal gap between restorations and teeth can cause leakage with its drawbacks including discoloration, dissolution of the luting agent, and pulpal irritation. It can also influence the ability of the restoration to withstand functional loading and consequently its durability ${ }^{(46)}$. In the current study, Vertical marginal gap distance was measured using an image analysis system, in which, software (Image $\mathrm{J}-1 \mathrm{~b}, \mathrm{USA}$ ) in combination with stereomicroscope (Olympus, SZ-PT: Japan) was used. This method reduces the chance of errors that may result from multiple procedures during sample preparation associated with other methods ${ }^{(46)}$.

Results of marginal gap distances for occlusal veneers restorations with the two preparation designs revealed that there was a no statistically significant difference between median marginal gap distances among the three materials used with minimally invasive preparation design before and after cyclic fatigue loading. These findings were in agreement with Daniele et al., $2018^{(28)}$, as they found no differences in the margins with two different preparation designs at time zero and after thermo-mechanical loading.

Resin composite material showed the highest mean value of gap distance before cyclic fatigue yet it showed the least mean value of gap distance after cyclic fatigue which means that composite was the least affected by fatigue loading. Moreover, for chamfer finish line preparation design, there was no statistically significant difference between hybrid ceramic and lithium di-silicate; and both showed statistically significantly higher median marginal gap distance than composite, these results could be due to the low stiffness and elastic property of the nano-ceramic reinforced resin composite that provide stress distribution that is concentrated around the loading point and not transmitted to the margins, on the other hand, ceramics create large internal stresses as a result of loading and transmit them to the marginal areas ${ }^{(47,48)}$.

The present study is a laboratory investigation with limitations such as lacking the complex oral environmental conditions including for example absence of the intra-pulpal pressure that may influence the quality of adhesion to dentin together with the acceleration of crack growth. So, controlled clinical trials are mandatory to assess clinical performance of materials and preparation designs before being recommended as a conservative biomimetic permanent solution for occlusally eroded or abraded posterior dentitions.

Within the limitations of this in-vitro investigation, the following could be concluded:

1. All the tested CAD/CAM materials showed fracture loads above the recommended minimum fracture strength for posterior restorations.

2. $\mathrm{CAD} / \mathrm{CAM}$ composite resin posterior occlusal veneers were superior to ceramic ones in terms of fracture resistance.

3. All tested materials in both preparation designs whether before or after fatigue loading, exhibited marginal gap distance not exceeding that described in the literature as acceptable range.

4. Controlled clinical investigations are mandatory to validate the clinical performance of such treatment option. 


\section{REFERENCES}

1. Guess PC. Influence of preparation design and ceramic thickness on fracture resistance and failure modes of premolar partial coverage restorations. J prosthetic Dent.2013; $110 ; 264-73$.

2. Magne P, Carvalho AO, Bruzi G, Giannini M. Fatigue resistance of ultrathin $\mathrm{CAD} / \mathrm{CAM}$ complete crowns with a simplified cementation process. J prothet Dent.2015; 114:5749.

3. Katrin H, Helena P, Alexander L, Friederike L, Reinhard H, Karl-Heinz K. Fatigue resistance of ultrathin CAD/ CAM ceramic and nano-ceramic composite occlusal veneers. Dent Mater 2019; 35:1370-1377.

4. Khan F, Young WG, Law V, Priest J, Daley TJ.Cupped lesions of early onset dental erosion in young southeast queenland adults. Aust Dent J 2001; 46:100-7.

5. Loomans B, Opdam N, Attin T, Bartlett D, Edelhoff D, Frankenberger R. Sever tooth wear: European consensus statement on management guidelines.J Adhes Dent 2017; 19:111-9.

6. Johansson A. Johansson AK, Omar R, Carlson GE. Rehabilitation of the worn dentition.J Oral Rehabil 2008; 35; 548-66.

7. Attin T, FIlli T, Imfeld C, Schmidlin PR. Composite Vertical bite reconstructions in eroded dentitions after 5.5 years; a case series. J Oral Rehabil 2012; 39:73-9.

8. Schlichting L, Maia H, Baratieri L, Magne P. Novel-design ultrathin CAD/CAM composite resin and ceramic occlusal veneers for the treatment of severe dental erusion. J Prprosthet Dent 2011; 105:217-26.

9. Burke FJ. Maximizing the fracture resistance of dentinbonded all ceramic crowns. J Dent1999; 27:169-73.

10. Anusavice KJ .Phillips' science of dental materials. St Louis, MO: Saunders; 2003.

11. Sundh A, Sjogren G. A comparison of fracture strength of yttrium- oxide-partially stabilized zirconia ceramic crowns with varying core thickness, shapes and veneer ceramics. Journal of Oral rehabilitation 2004; 31:682-8.

12. Beuer f, Schweiger J, Edelhoff D. Digital dentistry: an overview of recent developments for CAD/CAM generated restorations. British Dental Journal 2008; 204: 505-11.

13. Edelhoff D, Sorenson JA. Tooth structure removal associated with various preparation designs for posterior teeth. Int J Periodontics Restorative Dent .2002; 22: 241-249.
14. Valenti M, Valenti A .Retrospective survival analysis of 261 lithium di-silicate crowns in a private general practice. Quintessence Int.2009; 40: 573-579.

15. Leinfelder KF. Ask the expert. Will ceramic restorations be challenged in the future? J Am Dent Assoc 2001; 132; 46-7.

16. Magne P, Perakis N, Belser UC, Krejci I.Stress distribution of inlay-anchored adhesive fixed partial dentures: a finite element analysis of the influence of restorative materials and abutment preparation design. J Prosthet Dent 2002; 87; 516-27.

17. Vita Enamic, Vita Zahnfabrik, Germany. Technical product brochure. www.vita-zahnfabrik.com.

18. IPs Empress Direct,Ivoclar vivadent AG Schann, Liechtenstein. Technical product brochure.www.ivoclarvivadent.com.

19. Stappert CF, Att W, greds T, Strub JR. Fracture resistance of different partial coverage ceramic molar restorations: an invitro investigations .J Am Dent Assoc 2006;137-:514-522.

20. Guess PC, Zavanelli RA, Silva NR, Bonfante Ea, Coelho PG, Thompson Vp.Monolithic CAD/CAM lithium di-silicate versus veneered Y-TZP crowns comparison of failure modes and reliability after fatigue. Int. Jprosthodont.2010, 23 (5) 434-42.

21. Suarez, M.J.; Villaumbrosia, P.G.; Pradies, G. and Lozano, J.F.L.: Comparison of the marginal fit of Procera all-ceram crowns with two finish lines. Int. J. Prosthodont. 2003; 16: 229-232.

22. Gu H. and Kern, M.: Marginal discrepancies and leakage of all-ceramic crowns: influence of luting agents and aging conditions. Int.J. Prosthodont. 2003; 16: 109-116.

23. Felden A, Schmalz G, Federlin M, Hiller KA. Retrospective clinical investigation and survival analysis on ceramic inlays and partial ceramic crowns: results up to 7 years. Clin Oral Invest 1998; 2:161-7.

24. El-Mowafy O, Brochu JF. Longevity and clinical performance of IPS -empress ceramic restorations - a literature reviews. J Can Dent Assoc 2002; 68:233-7.

25. Kramer N, Frankenberger R. Clinical performance of bonded leucite -reinforced glass ceramic inlays and onlays after eight years Dent Mater 2005;21:262-71.

26. Sasse M, Krummel A, Klosa K, Kern M. Influence of restoration thickness and dental bonding surface on the fracture resistance of full-coverage occlusal veneers made from lithium disilicate ceramic. Dent Mater 2015; 31:907-915. 
27. Lima JM, Souza AC, Anami LC, Bottino MA, Melo RM, Souza RO .Effects of thickness, processing technique, and cooling rate protocol on the flexure strength of bilayer ceramic system. Dent Mater 2013; 29:1063-72.

28. Daniele A, Matteo D, Martina A, Andrea F, Giulio M. Influence of preparation designs on marginal adaptation and failure load of full-coverage occlusal veneers after thermomechanical aging simulation. J Esthet Restor Dent 2019; 31:280-289.

29. Hamza T, Al-Baili M, Abdel-Aziz M. Effect of artificially accelerated aging on the marginal fit and color stability of laminate veneers. Stomatological Dis Sci 2018; 2:1-7.

30. Nawafleh N, Hatamleh M, Elshiyab S and Mack F, Lithium Disilicate Restorations Fatigue Testing Parameters: A Systematic Review Journal of Prosthodontics 2016; 25:116-126.

31. Chitmongkolsuk S, Heydecke G, Stappert C. Fracture strength of all-ceramic lithium disilicate and porcelain fused-to-metal bridges for molar replacement after dynamic loading. Eur. J. Prosthodont Restor Dent 2002; 10:15-22.

32. Ahlers M, Morig G, Blunck U, Hajto J, Probster L, Frankenberger R. Guidelines for the preparation of CAD/CAM ceramic inlays and partial crowns. Int J Comput Dent 2009; 12:309-325.

33. Kern M, Thompson V, Beuer, F, Frankenberger R, Kohal R, Kunzelmann K, Pospiech P, Reiss N. 2017. All-Ceramics at a Glance. Society for Dental Ceramics, Ettlingen.

34. Ehsan H, Khalil F, James K, Jukka P, Edmond H. Static and fatigue mechanical behavior of three dental CAD/ CAM ceramics journal of mechanical behavior of biomedical materials 2015;59:304-313.

35. Loughran G, Versluis A, Douglas W. Evaluation of subcritical fatigue crack propagation in a restorative composite. Dent Mater 2005; 21:252-261.

36. Watchman J, Cannon W, Matthewson M. 2009. In: Mechanical Properties of Ceramics 2nd ed. John Wiley and Sons, USA.

37. Andrew C, Antheunis V, Daranee T, Swati A. Fracture strength of CAD/CAM composite and composite-ceramic occlusal veneers. Fracture strength of CAD/CAM composite and composite-ceramic occlusal veneers. J Prosthet Rese 2014; 58:107-114.
38. Leung B, Tsi J, Matinlinna J, Pow E. Comparison of mechanical properties of three machinable ceramics with an experimental fluorophlogopite glass ceramic. J Prosthet Dent 2015; 114:440-446.

39. Kassem A, Atta O, El-Mowafy O. Fatigue resistance and microleakage of CAD/CAM ceramic and composite molar crowns. J Prosthodont 2012; 21:28-32.

40. Magne P, Schlichting L, Maia H, Baratieri L. In-vitro fatigue resistance of CAD/CAM composie resin and ceramic posterior occlusal veneers. J Prosthet Dent 2010; 104:14957.

41. Chenfeng C, Flávia Z, Niek de J, Cornelis J, Kleverlaanb Albert J. The fracture resistance of a CAD/CAM Resin Nano-Ceramic (RNC) and a CAD ceramic at different thicknesses. Dent Mat 2014; 0:954-26.

42. Magne P. Immediate dentin sealing: a fundamental procedure for indirect bonded restorations. J Esthet Restor Dent 2005; 17:144-154.

43. Christine Y, Mattias K, Mohamed S. Influence of various bonding techniques on the fracture strength on thin CAD/ CAM fabricated occlusal glass ceramics veneers. J Mech Behav Biomed Mater 2017, 75; 504-5011.

44. Al-Akhali M, Chaar M, Elsayed A, Samran A, Kern M. Fracture resistance of ceramic and polymer-based occlusal veneer restorations. J Mech Behav Biomed Mater 2017; $74: 245-250$.

45. Guess P, Schultheis S, Wolkewitz M, Zhang Y, Strub J. Influence of preparation design and ceramic thicknesses on fracture resistance and failure modes of premolar partial coverage restorations. J Prosthet Dent 2013a; 110:264-273.

46. Iş1 D, Atilla S, Tugba Toz-Akalınc, Mutlu Z. Effect of material and fabrication technique on marginal fit and fracture resistance of adhesively luted inlays made of CAD/CAM ceramics and hybrid materials. J Adhes Science and Technology 2017; 31:55-70.

47. Kelly J, Rungruanganunt P, Hunter B, Vaiati F. Development of a clinically validated bulk failure test for ceramic crowns. J Prosth Dent 2010; 104:228-38.

48. Ohlmann B, Gruber R, Eickmeyer G, Rammelsberg P. Optimizing preparation design for metal-free composite resin crowns. J Prosth Dent 2008; 100:211-9. 